\title{
La «bolsa común» en las parejas: algunos significados y algunas trampas ${ }^{1}$
}

\section{Marta Ibáñez Pascual}

Universidad de Oviedo. Departamento de Economía Aplicada

Campus del Cristo. 33006 Oviedo

mibanez@uniovi.es

\section{Resumen}

Se plantea la enorme plasticidad de la idea de dinero en común o «bolsa común» en las parejas a partir del análisis del dinero doméstico, su propiedad, gestión y uso. Se seleccionan tres casos que se analizan como tipos ideales, en los que se comprueban las tensiones entre los marcos normativos considerados: el tradicional del varón proveedor, el comunitarista y el de la individualización propia de la segunda modernidad. Las conclusiones que nos permite este análisis son tanto de tipo metodológico como de resultados empíricos. Desde la metodología, se defiende el análisis de las relaciones de pareja a partir del estudio de caso. Los resultados empíricos se mantienen en la línea de las investigaciones en este campo: cierto refuerzo de la teoría de los recursos (el que ingresa el dinero está legitimado para ejercer mayor poder), que hay que matizar con la ideología de género y las «trampas» que comportan algunas decisiones vitales.

Palabras clave: dinero doméstico, «bolsa común», dinero en común, parejas, género, estudio de caso.

\begin{abstract}
Thru the domestic money analysis (its property, management and use) the enormous versatility of the idea of pooled money or the common purse of couples is considered. We select three cases, analyzed as ideal types, where is showed tensions between different normative patterns: the traditional breadwinner ideal, the communitarian one and the individualization related with the second modernity. The conclusions derived from this analysis are both of a methodological and an empirical kind. As for the methodology, we defend an analysis of the relations of couples on the basis of case studies, affirming that the keys of the analysis are provided by the biographical history, not only with respect to the past,
\end{abstract}

1. Este artículo es uno de los productos del grupo de investigación que se constituyó en el Área de Sociología de la Universidad de Oviedo en el año 1999, a raíz del proyecto Couples, Money and Individualization (ref.: SU 99 GRF 1) (parte de la Unidad Especial de Investigación 536 Reflexive Modernization, financiado por la Deutsche Forschungsgemeinschaft). Además de esta institución, hemos ido contando con el apoyo económico del Instituto de la Mujer del Principado de Asturias para el proyecto Parejas, dinero e individualización (ref.: FC02 IAM PG01102) y del Instituto de la Mujer español a través del proyecto Estudio de las relaciones de género y poder en los procesos de toma de decisiones en el ámbito privado. Una comparación internacional de las relaciones de pareja (ref.: MTA 02 INSTMUJER 10). 
but in certain cases also as to the future. The empirical results remain in line with the investigations in this field: reinforcement of resource theory (the one who brings the money in has legitimacy to exercise more power), which should be completed with elements of gender ideology and the "traps» that some crucial decisions entail.

Key words: domestic money, common purse, pooled money, couples, gender, case-studies.

\section{Sumario}

Introducción

La bolsa común: significados y trampas

Datos, método y dimensiones de análisis

La bolsa común en una gestión igualitaria

La bolsa común oculta desigualdades
La bolsa común como caricatura de comunalidad

Conclusiones

Referencias bibliográficas

\section{Introducción}

El dinero o «bolsa común», es decir, la unión de los ingresos de ambos cónyuges, es el marco general de organización del dinero doméstico. Parecería que los propios cimientos del concepto de bolsa común nos señalan una construcción comunitarista e igualitaria de la pareja, pues se supone que cada uno aporta según sus posibilidades y cada uno utiliza según sus necesidades, siempre entendiendo que el interés familiar se encuentra por encima del interés individual. Sin embargo, el dinero común puede estar ocultando desigualdades en diferentes esferas, todas ellas muy interrelacionadas: en el acceso, en el gasto personal, en el control sobre el dinero, en la valoración que se hace de la contribución de cada uno a los recursos de la pareja (Zelizer, 1989). En concreto, la propiedad, la gestión y el uso concreto del dinero doméstico van a constituir un área de análisis privilegiada, pues en su seno se reúnen ciertos conflictos cuya solución nos permite observar los grados de igualdad entre mujeres y varones en este terreno ${ }^{2}$.

La aparición o superación de las desigualdades en el terreno del dinero doméstico nos pueden estar indicando el grado en el que las relaciones íntimas se van democratizando, pues el análisis del acceso y uso del dinero nos permite observar otros aspectos de la relación de pareja, especialmente las relaciones de poder en su seno (Pahl, 1989, 1997, 1999). Más aún, las discusiones sobre dinero dentro del hogar operan de manera similar a las discusiones sobre

2. Históricamente, en el dinero doméstico se produce tensión en tres esferas distintas: las transferencias entre ganadores y no ganadores (normalmente, entre ganadores varones y no ganadoras mujeres), el consumo personal (para satisfacción propia) que pueda realizar la mujer — sobre todo, si no es ganadora del dinero-y, por último, el valor que se le da al dinero que gana la mujer (Zelizer, 1989). 
toma de decisiones en el terreno político general. Siguiendo a Carolyn Vogler, se pueden conceptuar las diferentes formas de gestión económica dentro del hogar como sistemas micropolíticos asociados a tipos distintos de democracia (Vogler, 1998).

El conjunto de teorías que han desarrollado la relación entre dinero, desigualdad y poder en las parejas han asumido dos grandes orientaciones: la teoría de los recursos de poder y la «sociología del género» (Vogler, 1998). En su visión más sencilla, la teoría de los recursos defiende la idea de «quien paga manda» para explicar las interrelaciones de pareja. En este sentido, Blood y Wolfe (1960), en su ya clásica investigación, encontraron que el miembro de la pareja que aportaba los mayores ingresos disponía de mayores probabilidades de tener una posición dominante.

Como Vogler plantea (1998) - y han podido comprobar numerosos investigadores (Burgoyne, 1990; Pahl, 1995; Nyman, 1999; Dema, 2006)—, la teoría de los recursos de poder precisa matizaciones de cierto calado, pues, como explicación única, falla desde el momento en que no se cumplen empíricamente sus presupuestos. Es decir, la construcción de una pareja en la que se produzca el acceso y el uso igualitario del dinero doméstico no depende únicamente del porcentaje de ingresos que aporta cada uno. Por ejemplo, es necesario también conocer los factores ideológicos y culturales, y, entre ellos, especialmente los roles de género que adopta la pareja y su ideología sobre ello. En concreto, su posición en el continuum entre el discurso tradicional del varón proveedor frente al moderno, en el que ambos miembros de la pareja son coproveedores.

Tanto la «teoría de los recursos de poder» como la «sociología del género» asumen la desigualdad entre varones y mujeres en la esfera doméstica, aunque sus explicaciones no coincidan y terminen reproduciendo el viejo conflicto entre el punto de vista materialista y el idealista. Una tercera visión, la de la segunda modernidad, no intenta explicar las razones de la diferencia de poder en las parejas, pues, por el contrario, lo que plantea es su superación:

[...] a partir de los años sesenta de este siglo, comienza claramente una nueva época en la que los dos géneros (aunque en grados diferentes) pueden experimentar los beneficios y las cargas de la vida propia. (U. Beck, y E. BeckGernsheim, 1998: 138)

Según estos autores, los actores sociales han de moverse en un mundo de reflexividad, de incertidumbre y oportunidad. Las relaciones personales se construyen en el día a día, no hay modelos válidos, llegamos a la "destradicionalización» del mundo de lo privado. Giddens acuña un término interesante, el de «relación pura» (Giddens, 1998: 11-12), que tendría dos características básicas: por una parte, que aspira a la simetría (y, por lo tanto, cuestiona las relaciones de poder); por otra, que la posibilidad de disolución forma parte misma del compromiso. Desde esta perspectiva, los conceptos clave son «individualización», pluralización de modelos familiares y paso de una biografía estándar a una «biografía de elección», como diría Ulrich Beck (1997: 30). 
Estos autores no lo explicitan directamente, pero podríamos colegir de su planteamiento que las tendencias hacia una mayor individualización de la relación están asociadas con mayores niveles de igualdad y de comportamientos y actitudes acordadas. De manera que en aquellas parejas en las que la mujer tiene una aportación económica similar al hombre, se podría esperar que su interrelación fuese más igualitaria ${ }^{3}$. Sin embargo, ¿qué sentido tiene ese «aunque en grados diferentes» que planteaban los Beck en la cita anterior? ¿Están funcionando los roles de género para impedir la igualdad real, aunque en teoría se adopte una gestión que parece favorecerla (la bolsa común)?

En este contexto, el objetivo de este artículo es mostrar las distintas realidades que se agrupan bajo el ideal de dinero o «bolsa común», a partir del análisis del dinero doméstico, su propiedad, gestión y uso. Para ello, tras analizar el propio concepto de bolsa común, se describen la metodología y las dimensiones de análisis. En el bloque central del artículo, se desarrollan tres casos que se entenderán como tipos ideales: la bolsa común en las parejas de segunda modernidad; la bolsa común bajo cuya legitimación se ocultan desigualdades en el acceso y uso de los recursos económicos que no se reconocen explícitamente, y, por último, la pareja tradicional (varón proveedor y ama de casa a tiempo completo), que está viviendo una situación de crisis. Estos casos nos permiten observar los pilares del ideal de dinero común (especialmente la confianza en el otro) y las tensiones implícitas en el propio modelo (comunalidad e igualdad, preeminencia del varón proveedor, individualización). Con ello, se podrá comprobar que este modelo de organización familiar (la bolsa común) alberga, y en ocasiones esconde, un conjunto complejo de realidades, para cuyo análisis se hace imprescindible la perspectiva biográfica.

\section{La bolsa común: significados y trampas}

Las investigaciones sobre modos de propiedad y gestión del dinero en el hogar señalan que el dinero o bolsa común es el mayoritario (Pahl, 1989; Vogler, 1994; Laurie y Gershuny, 2000). También lo es en España (CIS, 2003) ${ }^{4}$ y se ha podido comprobar en investigaciones más cualitativas (Díaz y otras, 2004). Su origen parece encontrarse en la muy mayoritaria idea (Burgoyne y Rout, 2001) de que el matrimonio es un acuerdo entre iguales, en el que la confianza es la base de una relación que se busca igualitaria (no equitativa).

Las investigaciones sobre el dinero doméstico destacan dos características, presentes en todas ellas ${ }^{5}$ l las parejas pretenden que el dinero (tanto su propie-

3. En este sentido, es de destacar la comprobación de que el riesgo de divorcio es más alto cuando la contribución de ambos cónyuges a la economía doméstica es similar; se supone que porque es el punto en el que la obligación mutua es más débil (Rogers, 2004).

4. En concreto, el 62,6\% contestan a la pregunta (P8): «¿Cómo administran Ud. y su cónyuge/pareja los ingresos que perciben uno de Uds. o los dos?», situándose en: "Juntamos todo el dinero y cada uno toma lo que necesita».

5. Una revisión bibliográfica muy útil se puede encontrar en Waseem (2004). 
dad como su gestión) no «manche» la relación. Hay ciertas reglas de juego no escritas por las que no se hacen explícitos los conflictos en relación con estos temas. Una conducta que se puede explicar a partir de «la norma del dinero común» y del símbolo de confianza que supone. La segunda característica es la ocultación del conflicto entre la idea de «compartir en igualdad» que supone el matrimonio y la posición prevalente que tradicionalmente mantiene el varón dentro de la familia.

En la investigación de la que este artículo forma parte (Díaz y otras, 2004; Díaz y otras, 2006), se ha podido comprobar que las parejas analizadas defienden la bolsa común como modelo ideal de gestión, y de hecho es la que practican. Utilizando la terminología bourdiana, la idea de «dinero común» estructura la construcción de la pareja, y a la vez es estructurante, pues, sobre ella, se compone también un tipo de pareja.

La idea de dinero común parece muy central en la construcción de la pareja, en el sentido de que es algo que se sobreentiende, se entiende como «lo natural», lo obvio. Es un pool muy interiorizado: los matrimonios tienen un régimen económico de gananciales ${ }^{6}$; tienen una sola cuenta a nombre de los dos y ambos miembros tienen acceso libre a ella. El grado de interiorización de este «deber ser» del dinero común es muy fuerte y se nota en la carga emocional con que se habla de ello. De hecho, tener dinero propio está cargado negativamente. La negativa a considerar el dinero que cada uno gana como dinero propio se da en todas las parejas, que insisten (muchas veces con pasión) en esta visión de dinero común.

Por otra parte, el dinero común es estructurante, en el sentido de que está utilizándose como símbolo de la confianza sobre la que las parejas construyen su vida en común. Cuando interrogamos a las parejas sobre la importancia del dinero en su relación, éstas la minimizan. Tanto varones como mujeres, estiman que el dinero no interfiere en su vida de pareja ni les crea conflictos, pues su pareja tiene toda su confianza. Pero es común que relaten ejemplos de otras parejas en los que el uso del dinero sí los genera; son ejemplos en los que los gastos de uno de los cónyuges se realiza obviando las necesidades del grupo familiar. En otras palabras, la unión económica es un pilar en la relación de pareja que funciona, y lo es porque supone confianza. La confianza en lo económico, el saber que el otro tratará el dinero como un bien colectivo y no sólo como propio, es un elemento fundamental que mantiene unida a la pareja.

Pese a la importancia de la bolsa común, este modelo de organización también implica tensión entre los intereses individuales y la comunidad familiar (Burgoyne, 1990). Por una parte, está presente la idea de que el que gana el dinero tendrá más derecho a decidir qué se hace con él (teoría de los recursos

6. El derecho establece aquí como norma legal lo que es una antigua costumbre en la mayor parte del país, a excepción de Cataluña. La alteración de esta pauta sólo sucede en circunstancias especiales, como es el caso de las familias de empresarios, por ejemplo: la única pareja analizada en nuestro estudio que no adopta este modelo de gestión (Díaz y otras, 2004). 
del poder) y, por otra, el matrimonio se construye (sustenta) sobre la idea de "compartir en igualdad», y, por lo tanto, todo el dinero que entra en el hogar se ha de utilizar de forma igualitaria, sin tener en cuenta quién hace los ingresos en la bolsa común. A esta dicotomía, se le añaden otros aspectos de las relaciones de pareja que pueden explicar distintas situaciones en la gestión y el uso del dinero doméstico. En concreto, resulta de especial interés ciertas reflexiones sobre la negociación en la pareja, el análisis de la interacción y la «economía de la gratitud» y, por supuesto, la perspectiva de género.

Una de las hipótesis de partida en esta investigación es que, en las parejas con un planteamiento más igualitario, se producen mayores procesos de negociación. La lógica interna vendría de la mano de la teoría de la segunda modernidad: si las parejas se van formando a partir de los intereses individuales de cada uno y los roles aprendidos (y, con ellos, la tradición y las diferencias de género) no tienen tanta importancia, es de esperar que observemos más procesos de negociación en su seno. El dinero, al ser la unidad de intercambio general, puede ser el escenario privilegiado sobre el que se discuta de forma racional (en este sentido estamos entendiendo "negociación»). Dicho con otras palabras, se podría esperar que las parejas modernas (mejor dicho, de la segunda $\operatorname{modernidad}^{7}$ ) desarrollasen todo un proceso de negociación en torno al uso individual del dinero.

También nos puede ayudar a entender la interacción en el seno de las parejas lo que Hochschild (1989) llamó la «economía de la gratitud», que plantea que las relaciones amorosas de pareja se basan en la gratitud que genera recibir las atenciones del otro como un regalo, que se acompaña con el deseo de devolver el favor.

Investigaciones con perspectiva feminista han matizado algunas de estas explicaciones. Por ejemplo, frente a la idea del intercambio amoroso de la «economía de la gratitud», parece ser que los maridos tienden a considerar el amor femenino (los cuidados y las atenciones «extra») como parte del rol de esposa, es decir, lo dan por supuesto, y no siempre entran en el intercambio (Jónasdóttir, 1991). O, igualmente, es común que al varón le guste definirse como proveedor principal y tienda a considerar las aportaciones femeninas como «externas al presupuesto familiar»; mientras que, sin embargo, en la práctica, las mujeres suelan estar más dispuestas a los sacrificios económicos (Pahl, 1995).

La psicóloga y psicoanalista Clara Coria (1991) llega más lejos. Plantea que esta tensión se soluciona a favor del varón, pues, por el reparto de los roles en el hogar, los hombres ya tienen asignado el verdadero control sobre el dinero y, sobre todo, porque la independencia económica de las mujeres no les asegura la autonomía. Para esta analista, además de los obstáculos socioculturales y las discriminaciones concretas (como, por ejemplo, menor paga para tareas

7. Nos referimos a la tendencia de llevar la racionalidad y la defensa de los intereses individuales al terreno de lo privado y, por lo tanto, de la pareja. 
iguales por el hecho de ser mujeres), existen otro tipo de obstáculos que son subjetivos y actúan de manera inconsciente en una gran cantidad de mujeres, que hacen que el dinero esté sexuado y que ellas no se sientan cómodas en este terreno $^{8}$.

\section{Datos, método y dimensiones de análisis}

En la investigación amplia a la que se hacía referencia anteriormente (y de la que este artículo forma parte), se seleccionaron dieciséis parejas, tomando a cada una como un caso. Contamos con tres entrevistas de cada pareja: la primera, a la pareja junta y, posteriormente, tras un rápido análisis de ésta, las dos entrevistas individuales en las que se indagaba sobre aquellos temas que no quedaban claros tras la lectura rápida de la entrevista colectiva. Para elegir a estas dieciséis parejas, se optó por un muestreo cualitativo en el que se tuvieron en cuenta diferentes dimensiones, asociadas a hipótesis teóricas que consideramos relevantes.

La dimensión más importante recoge la comparación de los ingresos de varones y mujeres. En este sentido, se seleccionaron parejas en las que ella no tiene ingresos propios y se dedica a tiempo completo a ser ama de casa; del resto de parejas, de doble ingreso, parejas en que las mujeres ganan menos que los varones, en las que ganan más y en las que ganan lo mismo. Esta dimensión nos permite contrastar la teoría de los recursos de poder en dos aspectos que no siempre correlacionan: por una parte, sus propias conductas respecto al acceso y uso del dinero; por otra, hasta qué punto las parejas consideran legítimo que la igualdad se construya según estos parámetros.

Además, se tuvo en cuenta también la edad de las mujeres que forman las parejas, en la idea de que el cambio generacional puede estar asociado a distintos ideales de pareja, más o menos tradicional, o a visiones más o menos individualizadas. De igual manera, se optó por una selección de parejas de clases medias en su sentido más amplio, con niveles de estudio y tipos de trabajo muy variados, con y sin hijos y con distintas duraciones en su relación?'.

8. Los síntomas que ponen en evidencia la existencia de conflictos subjetivos en relación con el dinero son, en palabras de Clara Coria:

"[...] pudor al hablar de dinero, desconcierto ante montos grandes, desconocimiento de la economía extra hogareña, delegación de herencias, inhibición para poner precio a servicios profesionales, desazón por ganar más que los varones, dificultad para reconocer como propios los bienes conyugales, sentimientos de culpa por gastar dinero en beneficio propio, etc.» (<http://agendadelasmujeres.com.ar/notadesplegada.php?id=44>)

9. Una descripción y explicación pormenorizada de las características de la muestra cualitativa seleccionada se encuentra en Díaz y otras (2004: 51-72). Así mismo, para un resumen algo más amplio de las características metodológicas expuestas aquí, se puede acudir igualmente a Dema (2005). Las transcripciones se presentan en su versión original, por lo que en algunos casos aparecen giros lingüísticos asturianos. 
Se ha optado por el estudio de casos en la idea de que «[...] el estudio pormenorizado de un caso singular (persona o grupo), normalmente en su historia, lleva a la comprensión de la totalidad del fenómeno» (Giner y otros, 1998: 84). Entendemos que su utilización nos permite reconstruir el proceso de estructuración de la pareja y de las relaciones de género en la pareja, aprehendiéndolo siempre desde su propio contexto (Crompton, 2001), con el objetivo de comprender las razones que en cada caso han llevado o están llevando a un modelo u otro de organización de la pareja. Se entiende que las parejas constituyen sistemas complejos que hay que abordar desde su totalidad, es decir, tener una visión comprensiva e histórica de ellas. En este empeño, nos podremos encontrar con ciertas pautas que permitan la comprensión del modelo en el sentido weberiano de «tipo ideal», esto es, podremos seleccionar aquellas características que nos resulten relevantes desde alguna perspectiva para poder mostrar el proceso por el que las parejas llegan a un tipo de acuerdo económico o a otro, lo que significa para ellas y con qué reparto de poder está relacionado. Se pretende, también, poder extrapolar estrategias típicas (o como mínimo racionales y, por lo tanto, comunicables) frente a situaciones sociales conflictivas que pueden ser más o menos comunes.

Las situaciones conflictivas más directas giran en torno a la situación ya enunciada por Carole Burgoyne (1990) entre el ideal de dinero común —en el que se desdibuja quién realiza el ingreso y se consume según los intereses del grupo familiar - y la tendencia a que cada uno sea dueño del dinero que gana. Como se aprecia, frente al ideal igualitario y comunitarista de la bolsa común, podemos contraponer dos modelos alternativos: el del varón proveedor — que, por esta razón, está legitimado (tanto desde su punto de vista como desde el de su pareja) para llevar el liderazgo en las decisiones económicas familiares- y el modelo de gestión individual, que parece extenderse en ciertos países (Roman y Vogler, 1999) y entre algunos tipos de pareja — de segundas nupcias (Burgoyne y Morison, 1997) y parejas de hecho (Vogler, 2005). Nos encontramos, entonces, con tres ideales de la organización del dinero doméstico presentes en las sociedades actuales y a las que las parejas están expuestas (aunque no siempre se hacen explícitos): la bolsa común igualitaria, la ideología patriarcal del varón proveedor y la visión más individualizada de la segunda modernidad. Estos tres ideales de organización pueden estar presentes en las mismas parejas, en primer lugar, porque como ideales no siempre son explícitos, y, en segundo término, porque las prácticas no siempre coinciden con el ideal. Buena parte de nuestro trabajo consiste en contrastar los ideales que mantiene la pareja con sus prácticas concretas, todo ello bajo el paraguas de la «bolsa común».

El modelo de gestión general de las familias tradicionales es la bolsa común. Este modelo puede funcionar para legitimar un acceso y un uso diferencial a los bienes de la familia, pues se entiende que si ambos tienen los mismos derechos - como marca la ley y está asumido socialmente-, las posibles diferencias se deben a decisiones personales y, por lo tanto, libres. Una bolsa común que ha sido el modelo predominante en las familias tradicionales, de especia- 
lización y jerarquización de roles entre los sexos, al igual que puede ser el modelo de gestión de una pareja de orientación y conductas igualitarias. En este sentido, la pareja que presentamos en primer lugar se caracteriza por mantener una fortísima interiorización del dinero común, mientras que, a la vez, podemos etiquetarla de "pareja de segunda modernidad", sobre todo porque observamos procesos de negociación muy explícitos. Este caso de bolsa común se puede considerar como aproblemático, en el sentido de que no hay conflictos entre lo que los individuos dicen que hacen (y cómo se ven) y sus comportamientos concretos, que podemos extraer de las entrevistas.

En otras ocasiones, la situación no es tan clara. Por ejemplo, se analiza una pareja en la que el ideal de dinero común está ayudando a tapar el orden patriarcal en el que está instalada. En este matrimonio, observamos un claro conflicto entre su «deber ser», su ideal, que es ser una pareja igualitaria, y sus prácticas y su comportamiento cotidiano, en los que el varón lleva las riendas del conjunto de la economía familiar. En esta pareja, su afirmación de dinero común les hace iguales, y esta autopercepción de igualdad permite que su desigual poder y acceso a los recursos familiares no se haga explícito y, por lo tanto, no se convierta en un problema.

En estas dos parejas, el dinero común simboliza la confianza mutua: como se señalaba antes, no sólo está estructurado (en el sentido de que las parejas, por defecto, adoptan esta forma de gestión económica), sino que, a la vez, es estructurante, pues el dinero común significa o simboliza la confianza mutua sobre la que se construye el proyecto colectivo. Por último, se ha querido reflejar una situación de crisis. En el tercer caso expuesto, se podrá observar cómo la quiebra de la confianza distorsiona las definiciones tácitas de la propiedad y el uso del dinero, de forma que bolsa común no es sinónimo de propiedad común del dinero. En este caso, en una pareja donde el varón es el único proveedor, el ama de casa manifiesta un fuerte conflicto entre los valores igualitarios y su situación material, conflicto que se hizo explícito cuando él falló en su papel de proveedor.

\section{La bolsa común en una gestión igualitaria}

María y Manuel rondaban ambos los cuarenta y cinco años cuando les entrevistamos. Son pareja desde hace unos diez años y no tienen hijos. Ambos vienen de familia obrera y comparten cierta ideología de izquierdas asociada a la generación que fue más activa en la transición política española y asturiana. Un elemento especialmente relevante es la implicación de María en una asociación feminista de gran peso en su localidad; como mínimo, María dedica dos tardes a la semana a reuniones y a trabajo asociativo. Esta actividad, y la ideología que implica, parecen ser elementos fundamentales en la construcción de su identidad.

Reciben ingresos de dos vías: por la tienda de dietética en la que trabajan ambos y por el trabajo que desempeña él a tiempo parcial limpiando unos grandes almacenes. La tienda es su principal fuente de ingresos; María es su 
dueña, pues ella empezó con el negocio y es ella la que tiene el conocimiento sobre los productos que se venden; eso no es óbice para que él esté directamente implicado en la buena marcha del negocio, que entiende como familiar. Su trabajo a tiempo parcial es secundario, producto del deseo de la pareja de tener algo de dinero al que «echar mano" para los momentos difíciles.

Esta situación (tanto que la tienda es de la mujer, como que tengan dos fuentes de ingresos) no impide que consideren común la propiedad del dinero. A lo largo de toda la entrevista, se va comprobando que esta visión está muy interiorizada. Además, por la reiteración con que niegan la posibilidad de diferenciar el dinero de uno y de otro, se puede considerar que la idea de dinero individual está cargada negativamente. Por último, es un tema sobre el que no hay discusión: el dinero común no puede generar conflictos en la dinámica de la propia pareja, pues, en último extremo, siempre aparece el pilar de la confianza y cada uno confía en el gasto responsable del otro:

ENTREVISTADORA: ¿YY habéis tenido algún conflicto por...?

MANUEL: No.

ENTREVISTADOR: ¿Alguna vez?

MAnUel: No. Por temas de límites de dinero o... no, límites no. [Manuel, 674.]

MARÍA: Bueno, yo no podría, vamos a ver, yo entiendo que la pareja ye pa estar relajada, yo si tengo que estar tensionada y tengo que reñir por perres y tengo que reñir por cómo está la casa de limpia y tengo que reñir... Pa eso vivo sola ¿eh? Yo téngolo más claro que el agua. Vamos, ni un minuto me cuesta. Entonces tenemos gustos comunes. No ye que él sea de aforrar y yo de gastar a manos llenes ni yo de aforrar y él de gastar a manos llenes.

MANUEL: No, procuramos limitanos.

MARÍA: Los dos.

MANUEL: Pero bueno, yo me gusta una cosa y la compro.

MARÍA: O sea que somos bastante...

MANUEL: Tampoco es un tema...

MARÍA: Bastante medidos ¿¿no? Así, en esi aspecto de...

MANUEL: Yo creo que sí. Yo me gustan los juegos de ordenador, pues compro alguno.

MARÍA: A mí no se me ocurre decir pa qué cogiste tres juegos de ordenador, que los cogiste el otro día. No, porque yo considero que tien que saber si puede coger tres juegos de ordenador o no. [M \& M, 2622-36.]

Respecto al posible conflicto entre sistemas de valores planteado en el apartado anterior (comunitarismo, varón proveedor e individualización), se aprecia que el comunitarismo y la individualización pueden funcionar armónicamente. Por ejemplo, en el terreno del dinero doméstico, cuando aparece la alusión al dinero propio, o cuando se observa la gestión y los usos del dinero, es común que tanto el hombre como la mujer hablen como personas autóno- 
mas (en primera persona del singular) cuando se refieren a gastos y en general a actos concretos ${ }^{10}$, mientras que usan el plural, son parte de una comunidad, cuando se refieren a las intenciones con las que se actúa o los resultados de esa acción, pues comparten esas intenciones y los resultados les van a afectar a ambos ("procuramos», "a ver si somos capaces», "no nos interesa»).

María y Manuel nos demuestran que no se puede colegir que en aquellas parejas en las que se produce un fuerte comunitarismo económico (bajo el ideal de la "bolsa común») no se desarrollen procesos de individualización y negociación. María y Manuel no discuten sobre dinero, pero sí lo hacen sobre la división de trabajo y reparto de labores cuando se les hace la pregunta:

ENTREVISTADOR: ¿Cómo consideráis la forma de compartir que habéis descrito en términos de lo que dais y de lo que recibís?

Han establecido un claro reparto de labores domésticas y en el negocio: a cambio de que él abra por la tarde, ella se encarga de más tareas de la casa. Explican pormenorizadamente las razones y queda claro que quieren, que necesitan justificarse: a ella le gusta dormir la siesta, y él no siempre tiene los conocimientos necesarios para desempeñar esas tareas y, en muchos casos, no ve la necesidad de realizarlas.

Han llegado al reparto de tareas que tienen, porque ambos entienden que es el que les conviene más (a cada uno individualmente):

MARÍA: Al cincuenta por ciento.

MANUEL: Sí, yo también. Yo creo que vamos, que es el mismo trabajo, el mismo trabajo. A mí me conviene más, claro.

MARÍA: Y a mí me conviene más, pero...

MANUEL: Quiero decirte, yo igual digo, bueno, pues, al yo preferir hacer una cosa antes que la otra por supuesto, en principio parecería que recibo más que doy ¿̇no? Si escojo, pero bueno yo creo que de una manera o de otra, a ella también le conviene.

MARÍA: Que conste y que quede claro que yo hago más ¿̨eh? Ahí no vamos a bajar la rienda. (Risas.)

MANUEL: Bueno, sí en las cosas...

MARÍA: En casa.

MANUEL: De casa está claro. Eso está claro. Quiero decir, en las cosas de casa está claro que no haces más, haces mucho más. Eso clarísimo, ahora bueno hay un...

MARía: Pero, al revés...

10. «Manuel: Entos yo muches veces tengo que pararla. Claro: Oye, quería comprar esto pa la tienda. Pues no. Porque no lo va a vender y te supone por ejemplo cincuenta mil pesetas. Y oye, no nos interesa. yo soy más comerciante pa este tema.» [Manuel, 828-30; también en 850-60.] 
MANUEL: ....una especie de pacto...

María: A medies.

MANUEL: ...con respecto a un tiempo determinao, que yo prefiero estar en la tienda, aunque vamos descarao. Con tal de no fregar los cacharros (risas) prefiero estar cuatro horas seguidas en la tienda que media hora fregando los cacharros, por ejemplo. Aunque sea pues algo, aunque sea mucho más que fregar los cacharros ¿eh? Entonces, bueno, yo digo al cincuenta por ciento porque nos conviene a los dos. Ahora, bueno, yo a mí, por ejemplo, me conviene mucho.

MARÍA: Si no, nos turnaríamos, ten por seguro. (Risas.) [M \& M, 650-72.]

Aunque en este arreglo sí hay un tinte de diferencias de género desde el momento en el que ella matiza la visión que da su marido de haber llegado a un acuerdo totalmente igualitario ( $\mathrm{H}$ : una especie de pacto. /M: a medies/»); pues ella sigue siendo reivindicativa respecto a la falta de responsabilidad del varón en las tareas domésticas. Pese a ello, en esta pareja el acuerdo sobre el reparto pactado es muy claro («María: Si no, nos turnaríamos, ten por seguro»).

Por último, un apunte sobre la ideología de género y la posición del varón proveedor. En esta pareja, aunque la dueña del negocio es María, es Manuel el que lleva la gestión económica. Aunque ambos están informados de la situación económica, es el hombre el que está más pendiente de la situación de los múltiples pagos del negocio, y por las mañanas «va de bancos» mientras ella está en la tienda. Éste es un comportamiento que coincide con el que señala Clara Coria (1989), que resalta que las mujeres empresarias y autónomas, cuando se emparejan, tienden a ceder o encargar los trabajos de gestión económica del negocio a su hombre; gesto que produce un doble efecto: aumenta el compromiso del marido con el negocio y aumenta también su poder dentro de la pareja.

\section{La bolsa común oculta desigualdades}

Como se señalaba anteriormente, el dinero común puede ser utilizado para encubrir una relación desigual en la pareja. En este caso, la comunalidad de bienes muestra a los miembros de la pareja como iguales, pues, teóricamente, ambos tienen similar acceso a los recursos, y, así, se oculta una organización de pareja sexista. Éste es el caso de Fátima y Fernando.

Cuando entrevistamos a Fátima y Fernando, rondaban los cuarenta. Él es funcionario de carrera del grupo más alto y ella ocupa un puesto técnico, pero con un contrato temporal de jornada partida, lo que le hace tener que dedicar más tiempo al trabajo que él, aunque gana la mitad. Sus ingresos son altos para los estándares españoles, y su nivel de vida y gastos son los propios de las clases medias (pago de la hipoteca de la vivienda, compra de la segunda residencia en el pueblo de origen, costes de formación en ambos cónyuges). Esto, unido a que están criando a dos hijos pequeños, hace que tengan ya sus gastos comprometidos y, por lo tanto, poca capacidad de maniobra y de discusión. 
La organización económica de esta pareja parte de una «bolsa común» muy interiorizada: su matrimonio es en régimen económico de gananciales; tienen una sola cuenta a nombre de los dos; y todo el dinero que ingresan los cónyuges pertenece al «dinero común», pues ni el hombre ni la mujer tienen la idea de dinero propio $^{11}$.

La bolsa común es la organización que adoptaron desde el inicio de su relación. Fátima y Fernando unen su dinero desde que empezaron a salir juntos, en la Universidad. En esta época, la posición de cada uno respecto al otro es de igualdad: son dos estudiantes universitarios viviendo en la casa materna, que reciben algún dinero de su familia de origen y realizan trabajos esporádicos. Cuando salen juntos, comparten su dinero de una forma «natural»; dicho de otro modo, cada uno pone lo que tiene, según la situación en la que se encuentre (haciendo la mili, con trabajos esporádicos...) y lo usan para sus actividades conjuntas. En las bases de su pareja, a lo largo de sus primeros cuatro o cinco años de relación, se está asociando la bolsa común - como forma de gestionar el tiempo que pasan juntos - y una situación material y anímica de igualdad en la pareja.

A la situación igualitaria de partida, se une el hecho de que comparten, y en ocasiones, durante las entrevistas, defienden con ardor el ideal de pareja igualitaria. Por ejemplo, para Fátima el trabajo remunerado tiene una enorme centralidad: ha luchado mucho para ir consiguiendo sus sucesivos empleos, se está preparando para tener mayores posibilidades laborales (tres veces por semana, a la hora de la comida, va a una academia donde estudia inglés) y, sobre todo, no se imagina como ama de casa:

FÁtIMA: Yo se que no lo llevaría, que no lo llevaría bien. Porque el trabajar es estar desempeñando una labor social, por lo menos yo, a mí me gusta lo que hago; no sé, yo creo que estaría más infeliz y, de hecho, el tiempo que estuve sin trabajar lo llevé muy mal. Yo lo de hacer la comida y poner la comida y solamente eso y esperar a que llegue él..., es un modelo que yo no, no podría ¿eh? yo creo que no podría. (Risas.) [F \& F, 736-44.]

Por su parte, Fernando tampoco se imagina viviendo con una mujer cuya única vida sea la familia:

FERNANDO: ... estar casado con alguien que esté en casa todo el día lo veo complicado... [F \& F, 763-4.]

Y, además, resalta especialmente la importancia del doble ingreso familiar:

11. Al igual que observamos en la pareja de María y Manuel, en esta pareja está cargado negativamente el simple hecho de tener dinero propio y afirman que el dinero nunca les ha generado ningún conflicto en su vida de pareja. 
FERNANDO: ...tal como está la vida hoy para, para vivir, pues o hay que ganar mucho dinero uno o sumar dos sueldos ¿¿no? Si no, es difícil mantener un... ordinariamente las cosas. Habría que hacer tantas economías que entonces tendrías que renunciar a miles de cosas que hoy en día pues parece que están ya, como que son elementales, ¿no? [F \& F, 767-73.]

En suma, consideran que las parejas tradicionales de especialización de roles resultan, por una parte, obsoletas — pues hoy en día, con el nivel educativo de las mujeres, resulta absurdo imaginarse un mundo en el que éstas estuviesen supeditadas a los varones- y, por otra, ideológicamente reprobables:

FÁtıMA: [Hablando de las parejas tradicionales.] Crea unos desequilibrios de poder tremendos. De hecho, están matando mujeres todos los días. Yo creo que eso es, si el hombre es el que que manda sobre la mujer, el que trae el dinero, el que... Es un mal, que los males que tienen, los problemas que tienen las mujeres cuando..., cuando pasan estas cosas ¿no? Vienen de ahí. No creo que ese que ese modelo pueda equilibrar, yo creo que ha desequilibrado tradicionalmente. [F \& F, 785-93.]

Nos encontramos con una pareja que quiere verse y quiere dar la imagen de pareja simétrica. Cuando queda explícita alguna desigualdad entre ellos dos, a continuación hay algún tipo de justificación, tanto por parte de él como de ella, o bien ella deja claro que no es una imposición de él, que es lo que ella desea.

Pese a este deseo e ideal de pareja igualitaria, encontramos que su relación con el dinero dista mucho de este ideal. En primer lugar, porque es el hombre el que asume la gestión económica. Él es el experto en cuestiones monetarias, sabe lo que ganan y lo que gastan. Fernando es el que saca el dinero del banco y el que mira el saldo de la cuenta. Este control directo sobre el dinero coincide con su preeminencia en las decisiones de gasto, pues, cuando no comparten las mismas prioridades económicas y se generan conflictos, los gastos que acaban realizando son los que desea Fernando. Esta tendencia general se concreta en la adopción de las dos grandes decisiones económicas que ha tomado la pareja: la compra del piso y la de la casa del pueblo. En ambos casos, fue Fernando el que tomó la iniciativa, sin embargo, cuando compraron la casa de pueblo, fue con el rechazo inicial de Fátima. Fernando usó argumentos utilitaristas y cierto chantaje emocional, y ella terminó aceptando el gasto. Sin embargo, Fátima mantiene cierto malestar, pues esta inversión les ha llevado a estar en una situación de estrechez económica y tiene la sensación de que los arreglos que son importantes van muy despacio ${ }^{12}$.

Además, Fátima y Fernando tienen un acceso diferente al dinero común: el hombre controla el dinero y ella se lo pide. Ella se despreocupa de la gestión

12. Por ejemplo, la calefacción, que para ella es una necesidad básica, la pusieron hace unos meses, después de siete años viviendo en la casa. 
y puede no saber el balance de las cuentas, como tampoco sabe el estado de las compras a plazos. Le va pidiendo el dinero según va necesitando ${ }^{13}$ y, aunque ella tiene la tarjeta VISA, no la usa, entre otras razones, porque desconoce el saldo y sabe que en ocasiones están en números rojos. El que el hombre sea el gestor y que vivan en una situación de endeudamiento, hace que ella tenga que consultarle antes de realizar cualquier gasto. La situación de endeudamiento, junto con la actitud responsable de la mujer ante el dinero, le impide a ésta comportarse como una persona autónoma en el gasto. Pero, a la vez, la mujer apoya esa especialización y hace al hombre responsable de las grandes decisiones.

Por otra parte, cuando se hace explícita esta situación, la mujer da a entender que ella se ha desentendido por decisión propia, porque lo prefiere. En conjunto, Fernando asume el rol de principal proveedor de la familia y Fátima, el secundario.

Como hemos visto hasta ahora, nos encontramos con una pareja que vive en flagrante contradicción entre su «deber ser» — pareja igualitaria— y su realidad cotidiana, donde el varón ejerce un claro control sobre la bolsa común y la mujer parece desentenderse de la situación. ¿Cómo manejan esta situación? ¿Qué estrategias y mecanismos de legitimación están utilizando para afrontar el conflicto entre su ideal igualitario y una realidad cotidiana en la que destaca la posición del varón proveedor?

La estrategia más utilizada parece, sencillamente, la de no hacer explícita la situación de desigualdad; taparla, tanto a los ojos de los entrevistadores como a los suyos propios. En este sentido, el dinero común proporciona una estupenda coartada: son iguales, pues tienen el mismo acceso al dinero. Si alguno de ellos no utiliza esta posibilidad, se debe a su opción personal (y libre).

Además, en el proceso de formación de la pareja de Fátima y Fernando, coincide su ideología igualitaria y una situación de igualdad entre ambos, en la que empezaron a unir su dinero. Es ésta la imagen que guardan de sí mismos.

No parece que el proceso de diferenciación y jerarquía en la pareja haya sido gradual; más bien ha sido producto de ciertas decisiones que sientan nuevas bases. Nos estamos refiriendo a la decisión de Fátima de abandonar un trabajo estable y bien remunerado para volver a estar con Fernando ${ }^{14}$. Éste es un claro ejemplo de las "alternativas problemáticas y excluyentes» (Gerson, 1985; citado en Dema y Díaz, 2004); en la línea con las situaciones de doble vínculo, en las que la elección de cualquiera de las alternativas encierra consecuencias negativas.

13. Sorprende la manera en la que se lo pide, como si fuera prestado: «¿Tienes algo que me dejes?".

14. Cuando Fátima termina la carrera, la pareja se separa, pues ella se va a trabajar a una ciudad mediterránea a unos mil kilómetros de Asturias. Esta separación dura más o menos año y medio, hasta que ella abandona su trabajo (adecuado a su formación y con un contrato indefinido) y vuelve a Asturias para estar con Fernando. 
Es a su vuelta cuando empiezan a vivir juntos, y de nuevo entienden el pool como la organización económica más natural; pero, en este caso, su igualdad se resiente, pues Fernando tiene ya ingresos fijos, mientras que Fátima pasa estos años con continuos problemas laborales. Un segundo punto de inflexión parece que es el matrimonio: toman la decisión de casarse tras un año de crisis y separaciones de la pareja. Con el matrimonio, viene la compra del hogar familiar $y$, al año, el primer hijo.

FÁtima: Nosotros, cuando nos casamos, fue porque queríamos tener hijos, queríamos formar una familia, si no, no nos hubiésemos casado, después de tantos años de relación, de haber vivido muchas experiencias. No nos hubiésemos casado. [F \& F, 836-50.]

El matrimonio como signo de "constitución de la familia» puede ser un elemento explicativo. Por parte de ambos, se tiene interiorizado que el dinero está al servicio de la pareja o la familia, entendidas como entes superiores a los meros intereses individuales. La trampa de género puede estar acechando aquí: cuando el contexto de interacción pasa de ser de igual a igual a enfocarse en la familia, es quizá cuando aparecen los roles de género especializados.

Volviendo a los mecanismos que hacen posible esta convivencia entre el ideal igualitario de la pareja y su realidad, nos encontramos con una mayor capacidad argumentativa del varón. Como plantean los teóricos de la segunda modernidad, en las parejas actuales, construidas desde posiciones de base igualitarias, las decisiones se argumentan y se discuten. En este sentido, analizando el tipo de interacción que se produce en la pareja (y que pudimos observar directamente en la entrevista colectiva), se aprecia que Fernando está mucho más habituado a hablar en público, y lo hace con brillantez. Fernando habla más, y Fátima está pendiente de su discurso. Con mucha frecuencia, ella interviene, más que para expresar su postura, para reafirmar lo que dice Fernando o para acabar sus frases. El entendido en cuestiones económicas es él y ella le pregunta con asiduidad. En preguntas importantes, el hombre también solicita la opinión a la mujer, aunque a veces no espera la respuesta y sigue su propio discurso, que ella repite asumiéndolo como propio.

Cuando el conflicto se hace explícito y Fernando no consigue convencer a Fátima, la solución que se ha ido adoptando, por lo menos en las grandes decisiones de gasto, ha sido la de priorizar la opción del varón. En estas ocasiones, ella se retrae y espera su oportunidad. Por ejemplo, no participa en los arreglos de la casa del pueblo, a la que no le gusta ir. En esta actitud nos interesa destacar dos características: por una parte, la interiorización de Fátima de su papel secundario en la pareja, secundario en el sentido de que ella sí que tiene voz y voto, pero en los conflictos cede su posición y asume la de Fernando; por otra parte, para ella esta situación es transitoria. Fátima es una mujer que piensa mucho en el futuro: llegará el momento en que los hijos crezcan, ella tenga un trabajo fijo (para ello estudia inglés) y entonces, cree, estará en disposición de negociar con Fernando en condiciones de igualdad. 


\section{La bolsa común como caricatura de comunalidad}

Cuando conocimos a Pilar y a Pedro, tenían en torno a treinta y pocos años y llevaban unos quince de relación. Pilar es ama de casa a tiempo completo y Pedro es mecánico de montajes, lo que le obliga a trabajar por largas temporadas allí donde esté la obra. Tienen dos hijos pequeños, de cinco y ocho años. Y su situación económica en la actualidad es buena, pues los ingresos que llegan al hogar por el trabajo del varón, ascienden anualmente a unos 42.000 euros.

Los entrevistadores señalan que "parece que hay un problema de falta de comunicación entre ellos» y que al final de la entrevista "entre ellos dos estuvieron bastante tirantes». Esta observación es congruente con la sensación que produce la lectura de la entrevista: ella monopoliza la conversación, quiere hacer explícita su versión de los hechos; cuando él habla, en muchos momentos con la intención de apoyar la versión de su mujer, ella la niega. Tras la lectura de la entrevista colectiva, se puede deducir que están en crisis, y que ella siente una amargura mayor que él. Ésta es, casi con seguridad, la única pareja en la que las entrevistas individuales nos han dado más información que la colectiva.

Este matrimonio se entiende mejor si resaltamos dos hitos en su relación: 1) $\mathrm{Al}$ año de casarse, Pilar sufre una depresión tras dar a luz a su hijo mayor; en esta época están viviendo fuera de Asturias, en la ciudad de origen de Pedro. Ella se siente muy sola, percibe que la familia de él no la apoya e incluso intenta suicidarse (aunque parece más una conducta parasuicida para llamar la atención) [Pilar, 34-35]. La situación de su mujer le lleva a Pedro a buscar trabajo en la ciudad de origen de Pilar para que tenga a su familia cerca [Pedro, 36-38; 4143], aunque ella no reconoce expresamente esa intención de ayuda [P \& P, 3839]. 2) Que Pedro abandonase un trabajo estable en una multinacional para abrir su propio proyecto empresarial sin tener en cuenta la opinión de su mujer y que hubiese estado sacando dinero para ello sin decírselo. Han pasado dos años desde que cerraron la empresa y todavía la conversación está salpicada de continuas alusiones a ella (especialmente en la entrevista a Pilar). Él no da su brazo a torcer y defiende la decisión que adoptó [Pedro, 46-47], aunque, por lo pronto que sale en la conversación (excusatio non petita...), parece que se está defendiendo de la acusación de ella. Por parte de ella hay un antes y un después de esta decisión unilateral, que recuerda y sigue reviviendo con un profundo sentimiento de rabia, rabia que deja traslucir más claramente en la entrevista personal.

Ya centrándonos en la propiedad del dinero doméstico, ésta es la única pareja de nuestro estudio en la que a la pregunta de la entrevista:

ENTREVISTADOR: ¿Diferencias tu propio dinero del dinero común? [Pedro, 638.]

El varón responde que, en realidad, todo el dinero del hogar es suyo: 
PEDro: No, no, no, no. No hay dinero común, en realidad. Si lo pusiéramos como dices tú, sería todo mi dinero. [Pedro, 639-640.]

Mientras que, para la mujer, el dinero es de la familia, del matrimonio y de los dos niños. Incluso recalcando la prioridad que han de tener los pequeños:

PILAR: No, no. El dinero es de todos, de los cuatro. Entre el suyo, entre el mío. Porque yo ha habido un par de épocas ahí que me puse, entonces, eh, el dinero es de los cuatro, y primero se pagan todas las cosas, primero todo, y luego, si sobra, pues, prioritariamente, eh, lógicamente los niños, si necesitan algo son prioridad ellos, y luego nosotros. No caprichos, eh, prioridades. A caprichos vamos todos iguales. [Pilar, 484-488.]

Pese a esta primera afirmación de dinero común, es un ama de casa que es consciente de su "clase sombra», es decir, la situación económica y social en la que podría quedar tras una hipotética separación, y esta reflexión aparece constantemente, tanto en la entrevista a la pareja como a la mujer:

PILAR: Igual las amas de casa, pues, realmente, si te pones a las malas no tienes nada. O sea, por mucho que hayas trabajado y mucho que hayas hecho, en resumidas cuentas, si te encuentras de frente con un divorcio te vas a quedar con una pensión miserable, a lo mejor de treinta o sesenta mil pesetas, si tienes la suerte y te las da. [P \& P, 1633-1636; también en 1642-1643, 17441755; Pilar, 1514-1515.]

Lo que nos hace pensar que, aunque no de forma expresa, también considera que, en realidad y si surgen conflictos, el que puede ejercer la propiedad sobre el dinero es el varón. En caso de separación, por ejemplo, él dispondría de una ventaja estratégica.

Esta pareja tradicional en crisis vive un fuerte conflicto entre dos sistemas normativos: el que defiende la preeminencia del varón proveedor y el ideal comunitarista, pues aunque Pedro decía que, en realidad, todo el dinero es suyo, sin embargo, en esta pareja ambos mantienen el ideal de dinero común, pues ella lo dice expresamente y él, por una parte, resalta los derechos que tiene su mujer para hacer uso de ese dinero:

ENTREVISTADOR: ¿Y qué dinero consideras el dinero de tu pareja?

Pedro: Lo mismo [que yo]. [Pedro, 659-660.]

Y, además, centrándonos en las formas de gestión del dinero, se desentiende del uso concreto que pueda hacer ella, pues ésta es una pareja con reparto tradicional de roles por género, y la administración del dinero le corresponde a la mujer. En este sentido, un elemento curioso de esta pareja es el extraordinario acuerdo que mantienen sobre esta especialización... y su rigidez. 
Pilar es la gestora única del dinero. Es una actividad que realiza desde que se casaron y él le dio la nómina:

PILAR: Yo me acuerdo cuando me casé, que me dijo: «Bueno, ahí está la nómina. Si te llega, bien».

PEDRO: Repártela.

PILAR: Si te llega, bien y si no... No me dijo «te jodes», pero poco le faltó. (Risas.) [P \& P, 421-424.]

Hay un acuerdo total sobre este papel de gestora de la mujer. Pedro se desentiende completamente, incluso de una manera exagerada:

PeDro: Yo, es que como nunca opino en cuanto al dinero, siempre se lo paso a ella. No sé. ¿Qué harías con 300.000 pesetas? [P \& P, 832-833.]

ENTREVISTADOR: Y, bueno, ¿pensáis que deberíais, más bien, más que nada tú, pero bueno, pensar más o pasar más tiempo pensando en el dinero?

PEDRO: Yo ya tengo bastante con preocuparme de ganarlo, vamos. (Pausa.) [P \& P, 1139-1141.]

Es reacio a comprar cualquier cosa, pues es asunto de ella, e incluso cuando va a trabajar fuera y lleva dinero para gastos, si se le acaba, tiene que llamarla para que le mande más.

Ella asume el papel de gestora, al que le da una gran importancia, también de una forma extrema, e incluso no contempla la posibilidad de que no sea así.

ENTREVISTADORA: ¿Y cómo crees que se siente tu pareja con que te encargues tú de los asuntos económicos de la casa? (Pausa.)

PILAR: No lo sé. Tampoco se lo voy a preguntar. O sea, ésa es mi regla. Si no quiere esa regla, pues, mira, se hablará de otros temas. [Pilar, 623-626.]

$\mathrm{Al}$ varón le corresponde proveer a la familia, y es sobre lo que parece pivotar su vida: sobre el trabajo y sobre la relación con su mujer:

PEDRO: Y yo creo que es a través de esto sobre lo que gira un poco mi vida: el poderles dar, lo que te he dicho antes, el mayor bienestar a mi familia. $\mathrm{Y}$, bueno, en realidad, mis metas personales prácticamente están cumplidas con el día a día en el trabajo; y luego con el poder darle lo que..., el fruto de ese trabajo a mi familia. Es un poco sobre lo que gira mi vida. Una vida muy poco complicada. Es lo típico, irse del trabajo a casa y de casa al trabajo. [Pedro, 50-55; también en 29-30; 35-36.]

Incluso parece que se desentiende de otras necesidades y aspectos, y su papel casi se reduce a proveer económicamente; por ejemplo: el trabajo que tiene ahora es mejor porque consigue más dinero y eso compensa que pase largas temporadas fuera: 
PEDRO: La cosa de que les das más de lo que podrías darles estando aquí, entonces, para mí, vamos, indudablemente compensa lo uno con lo otro pero con creces. [Pedro, 437-439.]

Podríamos decir que su capacidad de obtener dinero para su familia es un elemento central de la construcción de su propia identidad.

En general, es una pareja que le da mucha importancia al dinero. Incluso sorprende la centralidad que le conceden tanto el hombre como la mujer: los trabajos se valoran según los ingresos que se obtiene de ellos [Pedro, 302-303; 333-338], él está orgulloso de su capacidad para obtener dinero y mantener a su familia en unos estándares de vida altos, ella llega a decir que Pedro no podría ser su pareja si no pudiese cumplir con ese cometido... ¿Qué papel está cumpliendo el dinero en esta pareja?

La especialización de roles en la obtención y gestión del dinero doméstico ejemplifica la organización de la pareja en su conjunto. Ésta es una pareja joven en la que el reparto y la especialización de roles es extremo. En esta especialización de roles también nos encontramos con un reparto tradicional del poder, pues es el varón el que decide en todo momento dónde y por cuánto va a trabajar, sin atender a las indicaciones de ella. Es curiosa la relación de «despotismo ilustrado» de Pedro (todo para su mujer pero sin atender a las opiniones ni a los deseos de ella). Por ejemplo cuando, contestando a la pregunta «La decisión de venir a Asturias, ¿¿de quién fue?», nos cuenta:

Pedro: Mía. Total y absolutamente mía, vamos. De hecho, vamos, mi mujer en principio no quería, porque, bueno, ya te digo, yo estaba allí en un puesto fijo y me había costado tres años y pico el, el conseguirlo, no porque me costara promocionar o lo que fuera, pero bueno, por el tiempo que nos tuvieron así esperando, y, bueno. Y, ya te digo, un fin de semana, de los tantos que veníamos aquí, a casa de mis suegros a pasar el fin de semana, pues, en el periódico vi el anuncio de "XXX", me presenté a las pruebas, y como surgió bien, como surgió la cosa bastante bien, pues le quise dar la alegría. Al final, prácticamente hubiera sido mejor quedarnos allí, porque, en cuanto al trabajo quiero decir. Pero, bueno, es una cosa que, ahora, hoy por hoy no me, no me arrepiento en absoluto, vamos. Ya te digo, fue una decisión totalmente personal. De hecho, ella me dijo en varias ocasiones que no, que no viniéramos. De hecho, venía con menos sueldo aquí a "XXX». Pero, bueno, preferí el, el darle un poco más de estabilidad en cuanto a la, a la relación de pareja o a la, a la calidad de vida, que no al dinero. Lo cual es un error, pero, bueno. [Pedro, 83-96.]

El último comentario «es un error darle mayor importancia a la calidad de vida que al dinero" puede darnos algunas claves sobre la relación de Pedro con el dinero. Parecería que, frente a las peticiones de su pareja, la posición de Pedro es que, una vez que se ha llegado al acuerdo de constitución de la pareja y ésta es del tipo de especialización de roles, lo fundamental es cumplir con la parte con la que te has responsabilizado; en el caso masculino, proveer eco- 
nómicamente. El reproche sólo se acepta si no se cumple debidamente con la parte que toca. La crisis por la que están pasando es producto de que, cuando quiso montar la empresa, él se despidió de la multinacional y dispuso del dinero sin consultarla a ella. Él sigue considerando que tenía todo el derecho, y permite los reproches de ella y un control tan estricto sobre sus gastos porque la empresa fracasó, y no porque no contase con su mujer.

No resulta fácil extraer de las entrevistas las razones por las que Pedro no tiene en cuenta las opiniones de su mujer. A lo largo de la entrevista, sencillamente describe lo que hace, deja claro que es él el que ha de tomar las decisiones y considera, por la manera de decirlo ${ }^{15}$, que está cargado de razones. Aunque nunca lo dice explícitamente, se puede colegir que tiene muy interiorizada la ideología patriarcal de varón proveedor.

Sin embargo, no es ésta la visión de su mujer. La posición de Pilar presenta una mayor complejidad; pues, por una parte, asume que la función de su marido es la de proveer a la familia, y lo plantea, de nuevo, de una forma extrema:

PILAR: ...si él no trabaja, no es mi pareja. [Pilar, $253^{16}$.]

Aunque, por otra parte, mantiene sentimientos ambivalentes, pues, por ejemplo, acusa a su marido de no preocuparse suficientemente de ella o de no ayudar bastante en la crianza. Además, parece que el trabajo de él tampoco es suficiente (recordemos que gana 3.600 ? al mes) y considera que ella ha puesto más en la relación:

PILAR: Y yo le di mucho tiempo de mí, o sea, tiempo que era de pareja, para que el se desarrollara, sin embargo, él a mí no me lo ha dado. [Pilar, 217-219; también en 268-270.]

Por supuesto, los conflictos interpersonales suelen ser producto de múltiples causas y situaciones interrelacionadas; sin embargo (por lo pronto que sale en las entrevistas y sus continuas referencias), parece que, para Pilar, la confianza se quebró cuando él no le dijo nada, dejó su empleo estable y sacó el dinero de la cuenta para montar su propio negocio: aquí está la situación conflictiva. Lo que no resulta fácil de aclarar, son las razones últimas de esta frus-

15. Pedro: No tengo ningún tipo de remordimientos ni de dudas de si hice bien o si hice mal. [Pedro, 46-48.]

16. ENTREVISTADORA: ¿Y desde la otra perspectiva, para ti es importante el trabajo que él desarrolla, el trabajo que él hace?

PILAR: Es que sin trabajo no se come. O sea, el trabajo es trabajo. Si no trabaja él, vamos a poner, si él no trabaja, no es mi pareja, eh, es que el dinero no te llueve del cielo, en una palabra. También puede ser que, bueno, a ver, ¿qué pinta él en tu vida? Bueno, pues lo quiero, a mi forma lo quiero. Es que necesitas una pareja, o sea, hay unas cosas que es que..., y a mí no me da más por ir picoteando en todos los sitios, o sea, más o menos él me cubre mis necesidades, que hay unas que están más escasas que otras. [Pilar, 250-258.] 
tración, pues en la ecuación encontramos valores y demandas no siempre congruentes. Pues ella considera que tiene que tomar parte en las decisiones de su pareja (comportamiento de mujer moderna) y, sin embargo, ve que, cuando Pedro no le da esa opción, se encuentra con que no tiene manera de hacer oír su voz (situación material del ama de casa). Sin embargo, parece que la quiebra se hace explícita porque el negocio fracasa y las economías domésticas peligran. Podríamos suponer que si no hubiese sido así el conflicto, no se habría verbalizado y, más aún, no se habría materializado.

La situación de Pilar no es muy halagüeña, sobre todo si tenemos en cuenta que tiene muy presente su «clase sombra». En su ecuación, ser ama de casa supone ser dependiente y, por lo tanto, tener que aguantar:

PILAR: Yo, por ejemplo, mi hermana la que está trabajando no soportaría esa situación. Se pone: «Yo eso no lo aguanto», y yo: «Ya, pero tú tienes una nómina y eres totalmente independiente». [Pilar, 538-540.]

¿Cómo soluciona esta situación? En parte, pensando en el futuro. En la actualidad, Pilar aspira a montar un pequeño negocio que le proporcione independencia:

PILAR: ¿Planes?, bueno, pues, me imagino que, cuando me vea un poco holgadita económicamente, pues, sí. O sea, soy muy inquieta y seguramente, pues, me da por montar un negocio, pequeñito, eh, o sea, sin invertir mucho, no vaya a ser que me salga mal, y ya que como con el otro pufo ya tuvimos bastante. Eh..., pero no para llevarlo yo todo el tiempo, eh. O sea, para, bueno, pues que me de una serie de libertad y, bueno, pues. Claro, [...], porque te lo voy a decir, hoy en día, las mujeres amas de casa no tienen nada, entonces, bueno, por mucho que barras, siempre va a ser poco. [Pilar, 281-288.]

\section{Conclusiones}

La primera conclusión, a partir de los casos presentados, y de acuerdo con el conjunto de investigaciones en este campo, es que detrás de la idea de bolsa común se puede observar un mismo leitmotiv: la confianza en el otro. La bolsa común es un elemento estructurado y estructurante en la construcción de la pareja, pues está simbolizando la confianza mutua; además, la utilización "correcta» de esta bolsa común (re)genera a su vez la confianza de la que parte. Cuando se quiebra esta confianza, el pilar de la bolsa común deja de ser estructurante, pues los propios cimientos de la pareja se tambalean.

Una segunda conclusión que se extrae de nuestro análisis es que el dinero común no está reñido ni con la igualdad entre los integrantes de la pareja ni con el grado de modernidad de ésta, en el sentido de estar formada por individuos autónomos con intereses propios que han de llegar a acuerdos sobre su convivencia cotidiana.

El papel protagonista de las mujeres a la hora de construir la igualdad, se observa en diferentes situaciones (Díaz y otras, 2004) y está estrecha- 
mente relacionado con la ideología de género de la pareja y, sobre todo, con la «combatividad» femenina para defender una posición de coproveedora en igualdad con el varón. En otras palabras, la construcción de la simetría tiene protagonismo femenino (Stocks, 2005). Si la mujer no tiene una voluntad expresa de construcción de pareja simétrica, va a ser menos probable que su pareja se encamine en esa dirección, pues en algún momento se encontrará con ese "orden natural de las cosas» que es la organización patriarcal tradicional.

Detrás de la bolsa común, nos encontramos con mundos muy distintos, parejas que están implicadas en relaciones enormemente variadas. En este sentido, si algo puede aportar la metodología del estudio de casos, es la posibilidad de entender, interpretándolos, los procesos de construcción de la pareja: sus bases de confianza y cómo la biografía de cada pareja (deseos previos, situaciones dadas y decisiones frente a esas situaciones) va construyendo un tipo de relación. De la misma manera, también podemos extraer situaciones en las que entran en conflicto ideales contrapuestos, o situaciones en las que el ideal de vida no se corresponde con las prácticas cotidianas. Frente a estos conflictos, resultan ilustrativas las diferentes estrategias que adoptan las parejas para encararlos.

Por ejemplo, la complicada interrelación entre la posición material y la ideología. No es extraño que las parejas mantengan un ideal de convivencia igualitario, que la mujer aporte a la comunidad de bienes ingresos inferiores y que el varón ostente una posición de mayor poder. Y tampoco sorprende que las parejas hayan llegado a esta situación porque la mujer haya colocado su relación de pareja por delante de su carrera laboral. En suma, la posición material (menores ingresos que coinciden con menor poder) se ve reforzada por la propia ideología de género.

Por otro lado, en parejas en las que sólo hay un proveedor, resulta difícil hablar realmente de dinero común, especialmente cuando aparecen los problemas y, con ellos, una "clase sombra» de la mujer muy inferior a la que disfruta con su marido. Además, estos problemas pueden estar relacionados con el conflicto entre los valores patriarcales del varón único proveedor y el deseo de las mujeres de ser tratadas como iguales, pues nos encontramos con mujeres que, aunque amas de casa a tiempo completo, tienen profundamente interiorizados los valores igualitarios (no en vano es seguramente la ideología más potente de todas a las que están expuestas las parejas actuales) y que ya no se resignan a tener una posición secundaria.

Por último, son también ejemplificadoras algunas estrategias observadas de superación del sempiterno conflicto entre los intereses individuales y la visión comunitaria de la familia. La primera, la que señalan la mayor parte de las investigaciones cualitativas sobre este aspecto (Waseem, 2004): no hacerlas explícitas. Otra muy común parece ser: derivar la solución de los problemas a un esperanzador futuro; en este sentido, de nuevo la metodología biográfica puede ser la forma adecuada de análisis para ulteriores indagaciones. 


\section{Referencias bibliográficas}

BECK, U.; BECK-GERNSHEIM, E. (1998). El normal caos del amor: Las nuevas formas de la relación amorosa. Barcelona: Paidós.

BECK, U.; GIDDENS, A.; LASH, S. (1997). Modernización reflexiva: politica, tradición y estética en el orden social moderno. Madrid: Alianza.

Blood; Wolfe (1960). Husbands and Wives. Nueva York: New York Free Press.

Burgoyne, C. (1990). "Money in marriage: how patterns of allocation both reflect and conceal power». The Sociological Review, vol. 38, no 4.

Burgoyne; RouTH (2001). «Beliefs about financial organisation in marriage: The "Equality Rules OK” Norm?». Zeitschrift fuer Sozialpsychologie, 32, p. 162-170.

Burgoyne, C.; Morison, V. (1997). «Money in remarriage: keeping things simple and separate». The Sociological Review, vol. 45, no 3, p. 363-395.

CIS (2003). Familia y género (International Social Survey Programme). Estudio no 2.529 .

Coria, C. (1991). El sexo oculto del dinero. Barcelona: Paidós.

Crompton, R. (2001). "Gender, comparative research and biographical matching». European Societies, vol. 3, no 2, p. 167-190.

Dema Moreno, S.; Díaz Martínez, C. (2004). «La construcción de la igualdad en las parejas jóvenes: de los deseos a las prácticas cotidianas». INJUVE.

Dema Moreno, S. (2005). «Entre la tradición y la modernidad: las parejas españolas de doble ingreso». Papers, no 77, p. 135-155.

- (2006). Una pareja, dos salarios. El dinero y las relaciones de poder en las parejas de doble ingreso. Madrid: CIS (Colección Monografías).

Díaz Martínez, C.; Díaz Méndez, C.; Dema Moreno S.; Ibáñez Pascual, M. (2004). Dinero, amor e individualización: Las relaciones económicas en las parejas/familias contemporáneas. Oviedo: Instituto Asturiano de la Mujer y KRK ediciones.

Díaz Martínez, C.; Dema Moreno S.; IbáÑez Pascual, M. (2007). «The intertwining of love and money in couple relationship». En: STOCKS, J.; DÍAZ, C.; HalleröD, B. Modern Couples sharing money, sharing life. Hampshire: Palgrave MacMillan.

GERSON, K. (1985). Hard choices: how women decide about work, career and motherhood. Berkeley: University of California Press.

GIDDENS, A. (1998). La transformación de la intimidad: Sexualidad, amor y erotismo en las sociedades modernas. Madrid: Cátedra.

Giner, Salvador, LAMO DE EsPinOSA Emilio; TORRES, Cristobal (eds.) (1998). Diccionario de Sociología. Madrid: Alianza Editorial.

Hochschild, A. R. (1990). "The Economy of Gratitude». En: FranKs, D. D.; MCCARThy, E. D. (eds.). The Sociology of Emotions: Original essays and research papers. Greenwithc: JAI Press.

JÒNASDÓTTIR, A. G. (1991). Love, power and political interests: Towards a theory of patryarchy in a welfare society. Örebro: University of Örebro.

LAurie, H.; GershunY, J. (2000). "Couples, work and money». En: BerThOUd, R.; Gershuny, J. (eds.). Seven Years in the Lives of British Families. Bristol: Policy Press.

NYMAN, C. (1999). "Gender equality in "the most equal country in the world"? Money and marriage in Sweden». The Sociological Review, vol. 47, no 4, p. 766-793.

PAHL, J. (1989). Money and marriage. Basingstoke: MacMillan. 
- (1995). «His money, her money: recent research on financial organisation in marriage». JOEP, 16 (3), p. 361-376.

- (1997). Our money and my money: What do financial arragementes tell us about relationship. Seventh Jackie Burgoyne Memorial Lecture. University of Kent at Canterbury.

- (1999). Invisible money. Bristol: The Policy Press.

Rogers, S. J. (2004). «Dollars, dependency, and divorce: Four perspectives on the role of wives' income». Journal Marriage and Family, 66, p. 59-74.

Roman, C.; Vogler, C. (1999). «Managing money in british and swedish households». European Societies, 1 (3), p. 419-456.

Vogler, C. (1994). «Money in the household», en ANDERSON, M. y otros. The social and political economy of the household. Oxford: Oxford University Press.

- (1998). "Money in the household: some underlying issues of power». The Sociological Review, vol. 46, no 94, p. 687-713.

- (2005). "Cohabiting couples: rethinking money in the household at the beginning of the twenty first century». The Sociological Review, vol. 53, no 1, p. 1-29.

Waseem, S. (2004). «Household monies and decision-making». Policy Research Paper 23. Australian Government Department of Family and Community Services. ZELizer, V. (1989). "The social meaning of money: "special monies"». American Journal of Sociology, 95, 342-77.

- (1997). The social meaning of money. Nueva York: Basic Books. 